\title{
Horto Medicinal: Relógio do Corpo Humano
}

\author{
Medicinal Garden: Human Body Clock
}

Fabiane Habowski (fabianehabowski@yahoo.com.br)

Escola Estadual Técnica Guaramano

\begin{abstract}
Resumo: O relato descreve um projeto realizado com alunos do $2^{\circ}$ ano do Ensino Médio da Escola Estadual Técnica Guaramano em Guarani das Missões, RS, com plantas medicinais que foi planejado e desenvolvido pela Professora de Biologia e a turma tendo por objetivo principal proporcionar aulas mais dinâmicas, agregando teoria à prática educacional. O Horto Medicinal está localizado junto ao Viveiro da Escola, ou seja, na sua sede. Tem como área total 324 metros quadrados, dividido em 12 parcelas, onde cada uma corresponde a uma planta medicinal e a um determinado horário indicado para seu uso, como também o seu princípio ativo. As plantas medicinais são tradicionalmente utilizadas pelas famílias da comunidade local e sua vasta aplicação e variedades de espécies, faz com que se necessite aprimorar e obter mais conhecimentos sobre o assunto. Pode-se perceber que toda atividade prática contribui para a formação de alunos mais críticos e protagonistas quando podem desenvolver conteúdos de aula em projetos, pois são desafiados a encontrar soluções para os problemas que vão surgindo no decorrer do processo.
\end{abstract}

Palavras-chave: Horto; Plantas Medicinais; Educação Ambiental.

Abstract: The report describes a project carried out with students of the 2nd year of high school of Guaramano Technical State School in Guarani das Missões, RS, with medicinal plants that was planned and developed by the Biology Teacher and the class with the main objective to provide more classes. dynamics, adding theory to educational practice. The Medicinal Garden is located next to the School Nursery, that is, at its headquarters. Its total area is 324 square meters, divided into 12 parcels, each of which corresponds to a medicinal plant and to a specific time indicated for its use, as well as its active ingredient. Medicinal plants are traditionally used by families of the local community and their wide application and variety of species, makes it necessary to improve and gain more knowledge on the subject. It can be seen that every practical activity contributes to the formation of more critical students and protagonists when they can develop class contents in projects, as they are challenged to find solutions to the problems that arise during the process.

Keywords: Garden; Medicinal plants; Environmental education.

\section{INTRODUÇÃO}




\section{Vol. 2, n. 3 - Edição Especial: Ciclos Formativos em Ensino de Ciências.}

O presente relato tem como objetivo apresentar os resultados de um projeto realizado com alunos do $2^{\circ}$ ano do Ensino Médio da Escola Estadual Técnica Guaramano de Guarani das Missões, RS, turma esta escolhida por trabalhar no decorrer do ano letivo assuntos relacionados ao corpo humano no componente curricular de Biologia. Os objetivos principais do projeto foram de planejar e desenvolver um Horto Medicinal, dividido em 12 parcelas, com plantas medicinais conhecidas, como também, qual é o melhor horário para utilizá-las e qual a ação das mesmas no organismo. É também um espaço que oferece segurança de produção das plantas livres de agroquímicos e que didaticamente sirva de suporte para o conhecimento, facilitando o acesso de toda comunidade e preservando o ambiente e as espécies.

O estudo da Biologia, principalmente na educação básica pode gerar certa dificuldade, visto que o conhecimento abordado é muito vasto, tornando-se às vezes incompreensível por parte dos alunos, para Brasil (2006, p.):

\footnotetext{
Biologia é um componente curricular que engloba todo o conhecimento concernente aos seres vivos, procurando compreender e valorizar tanto os mecanismos que regulam as atividades vitais que neles ocorrem como mecanismos evolutivos das espécies e as relações que elas estabelecem entre si e com o ambiente em que vivem.
}

A necessidade de utilizar metodologias que façam com que o aluno possa compreender e perceber o conteúdo que está sendo explicado é cada vez maior, pois o aluno é instigado a pensar em soluções, tornando-se protagonista.

Os conteúdos de Botânica, muitas vezes, são abordados dentro de uma perspectiva tradicional de ensino, de forma totalmente desvinculada da realidade dos estudantes, o que impossibilita a conexão do conteúdo escolar à dinâmica da natureza e exclui os seres humanos como pertencentes das relações ecológicas visualizadas em sua aprendizagem (BITENCOURT, 2013, p.20).

Conforme Abdala (2014, p.2) "um dos problemas mais recorrentes do ensino de Botânica é a dificuldade dos professores em desenvolver atividades práticas que despertem a curiosidade do aluno e que demonstrem a importância daquele conhecimento no seu dia a dia".

Com isso, realizou-se o planejamento e execução de um Horto Medicinal, a fim de organizar em um espaço da escola algumas plantas medicinais, levando em 


\title{
Vol. 2, n. 3 - Edição Especial: Ciclos Formativos em Ensino de Ciências.
}

consideração seu uso, horário e ação no organismo, juntamente com alunos do $2^{\circ}$ ano do Ensino Médio. Pois, acredita-se, assim como segundo Krasilchik (1996, p.61), que:

\begin{abstract}
uma parcela significativa dos conhecimentos de Biologia é obtido por meio da observação direta dos organismos e fenômenos ou por meio da observação de figuras, modelos, etc. Ouvir falar de um organismo é, em geral, muito menos interessante e eficiente do que ver diretamente a realidade, o que justifica a realização de excursões, aulas práticas e demonstrações.
\end{abstract}

Por isso, faz-se necessário os projetos de educação ambiental nas escolas, pois os mesmos possibilitam aos alunos uma melhor compreensão e um olhar diferente para as questões ambientais.

\section{DESCRIÇÃO DAS ATIVIDADES}

O projeto Horto Medicinal: Relógio do Corpo Humano, foi planejado com o intuito de ter um espaço na escola destinado as plantas medicinais mais utilizadas e conhecidas, como também com informações sobre as mesmas, por isso a turma de $2^{\circ}$ ano do Ensino Médio, assessorados pela Professora de Biologia, num período de 2 meses fez um levantamento sobre as plantas medicinais mais conhecidas, seguindo de uma pesquisa bibliográfica das 12 plantas medicinais selecionadas.

Na sequência, analisou-se o melhor local na escola para implantação do Horto, de fácil acesso, tanto para o educandário, como para a comunidade, decidindo-se por uma área junto ao Viveiro Florestal, na sede da escola.

As plantas medicinais representam fator de grande importância para a manutenção das condições de saúde das pessoas. Além da comprovação da ação terapêutica de várias plantas utilizadas popularmente, a fitoterapia representa parte importante da cultura de um povo, sendo também parte de um saber utilizado e difundido pelas populações ao longo de várias gerações (TOMAZZONI; NEGRELLE; CENTA, 2006).

De acordo com a medicina chinesa e a teoria do relógio cósmico, cada hora no Relógio do Corpo Humano representa uma parcela correspondente a um órgão, por isso, decidimos por esta organização, onde em cada parcela são cultivadas plantas medicinais que auxiliam nos transtornos de saúde do órgão representado (Figura 1). 


\section{Vol. 2, n. 3 - Edição Especial: Ciclos Formativos em Ensino de Ciências.}
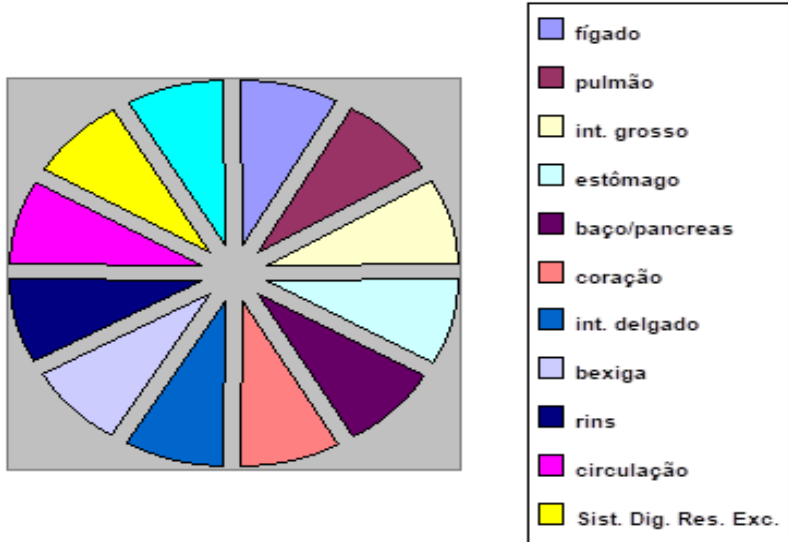

Figura 1- Parcelas do Horto com a indicação dos sistemas/órgãos envolvidos.

Após, pesquisou-se mais detalhadamente a ação da planta medicinal no organismo, como também seu horário, pesquisa esta que está em uma placa próxima ao Horto Medicinal (Quadro 1).

\section{SAÚDE PELAS PLANTAS MEDICINAIS}

\begin{tabular}{|c|c|c|c|}
\hline Horário & Órgão & Ação principal & Planta Medicinal \\
\hline $1 \mathrm{~h}$ às $3 \mathrm{~h}$ & Fígado & Produzir a bile. Eliminar substâncias nocivas. & Alcachofra \\
\hline $3 \mathrm{~h}$ às $5 \mathrm{~h}$ & Pulmão & Fornecer oxigênio aos órgãos através do sangue. & Pulmonária \\
\hline $5 \mathrm{~h}$ às $7 \mathrm{~h}$ & Intestino Grosso & $\begin{array}{l}\text { Reter a sobra dos alimentos que junto com a } \\
\text { água formam as fezes. }\end{array}$ & Hortelã \\
\hline $7 \mathrm{~h}$ às $9 \mathrm{~h}$ & Estômago & $\begin{array}{l}\text { Acumular os alimentos para que sofram a ação } \\
\text { do suco gástrico. }\end{array}$ & Boldo \\
\hline $9 \mathrm{~h}$ às $11 \mathrm{~h}$ & Baço e Pâncreas & $\begin{array}{l}\text { Relaciona-se com a circulação do sangue e com } \\
\text { a produção de enzimas. }\end{array}$ & Manjerona \\
\hline $11 \mathrm{~h}$ às $13 \mathrm{~h}$ & Coração & Bombear sangue para todo o organismo. & Alecrim \\
\hline $13 \mathrm{~h}$ às $15 \mathrm{~h}$ & Intestino Delgado & $\begin{array}{l}\text { Os alimentos passam para a circulação linfática e } \\
\text { sanguínea, sendo a seguir distribuídos a todas as } \\
\text { células do corpo. }\end{array}$ & Mil em rama \\
\hline $15 \mathrm{~h}$ às $17 \mathrm{~h}$ & Bexiga & Receber e acumular a urina. & Losna \\
\hline $17 \mathrm{~h}$ às $19 \mathrm{~h}$ & Rins & $\begin{array}{l}\text { Eliminar as impurezas existentes no sangue } \\
\text { formando a urina. }\end{array}$ & Carqueja \\
\hline
\end{tabular}

Quadro 1- Tabela indicando a planta medicinal e sua ação no organismo, como também o horário e órgão envolvido. 
Revista Insignare Scientia

\section{Vol. 2, n. 3 - Edição Especial: Ciclos Formativos em Ensino de Ciências.}

Após a escolha do local e o planejamento do horto, uma vez por semana toda turma foi até o Viveiro da Escola para a execução do projeto, como a delimitação das parcelas, adubação, plantio das mudas, irrigação, e demais cuidados. Também, após a finalização, uma vez por mês todos alunos da turma visitavam o Horto para realização de reparos (Figuras 3 e 4 ).
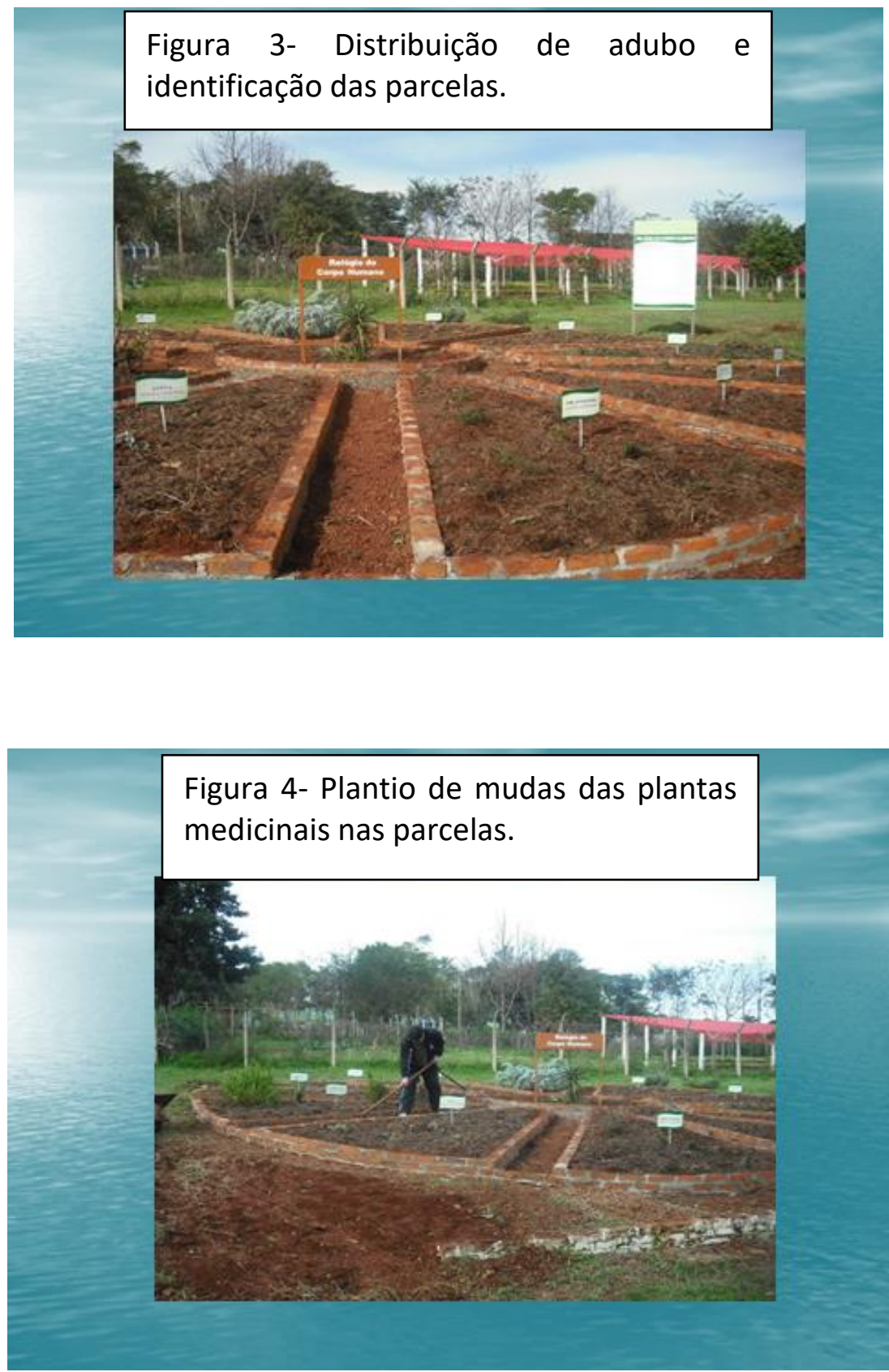


\section{Vol. 2, n. 3 - Edição Especial: Ciclos Formativos em Ensino de Ciências.}

O Horto Medicinal: Relógio do Corpo Humano ficou à disposição da comunidade e das outras turmas de alunos, sendo que a cada ano seleciona-se uma nova turma para continuar com o projeto.

As dimensões do Relógio do Corpo Humano são:

Largura $-18 m$

Comprimento $-18 \mathrm{~m}$

Caminhos ao redor do Relógio - $15 \mathrm{~m}$

Centro do relógio- $2 \mathrm{~m}$

Caminhos entre canteiros $-0,50 \mathrm{~m}$

Comprimento dos canteiros $-5 \mathrm{~m}$

Largura externa dos canteiros $-1,5 \mathrm{~m}$

Largura interna dos canteiros $-0,50 \mathrm{~m}$

Raio do Relógio parte externa $-42 \mathrm{~m}$

Área total do Relógio- $324 \mathrm{~m}^{2}$

\section{DISCUSSÕES DA PRÁTICA}

A partir deste projeto, pode-se percebe que os alunos aprovaram a metodologia aplicada, pois foram instigadas à pesquisa, ao planejamento, organização e execução de todas as etapas.

Os alunos explicitam esta ideia em alguns excertos retirados dos relatórios “como foi bom nós desenvolvermos este projeto, pois nos fez pensar mais, procurar soluções; conheci muitas plantas medicinais que nem sabia que existiam e para que serviam” (Aluno 1, 2016); “eu gostei por que tive que pesquisar bastante, até minha mãe me ajudou e me deu umas dicas" (Aluno 12, 2016).

O Horto Medicinal: Relógio do Corpo Humano é um estímulo para a participação dos alunos como também de professores de outras disciplinas, integrando e unindo conhecimentos para que o mesmo fosse implantado com sucesso. Haviam muitas dúvidas sobre as plantas medicinais com nomes diferentes e assim com a 


\section{Vol. 2, n. 3 - Edição Especial: Ciclos Formativos em Ensino de Ciências.}

identificação correta gerou-se mais segurança na utilização das mesmas. O aluno 5 (2016) por exemplo, relata que: “como é bom ir lá no viveiro da escola e ver um projeto nosso, que nós desenvolvemos e está lá para todos visitarem”. O que mais importa é que os alunos aprendam os conhecimentos necessários de forma articulada por que assim fará muito mais sentido para eles (SILVA, CAVALLET, ALQUINI, 2006, P.76).

As plantas medicinais cultivadas no Horto Medicinal possibilitam uma qualidade da matéria prima, pois, são cultivadas organicamente (limpas e sadias) sem o uso de agroquímicos, o mesmo preserva a natureza e a biodiversidade, resgata e valoriza os conhecimentos populares.

O espaço identifica corretamente as plantas medicinais evitando equívocos e acidentes com plantas tóxicas. Estimula-se a troca de conhecimentos entre as pessoas, propiciando a integração do saber popular e científico sendo o local destinado ao estudo e pesquisa. E também é um espaço educativo e didático para o conhecimento da natureza, evita o extrativismo e a extinção das plantas medicinais, estimulando o contato e o conhecimento da natureza e das plantas que nos auxiliam.

Com este projeto pode-se reforçar a importância do aluno relacionar a Biologia com o seu cotidiano, articulando conhecimentos e aprendendo os caminhos que devem percorrer para desenvolver a pesquisa.

\section{CONCLUSÃO}

Educar é saber ouvir, respeitar, observar e proporcionar novas experiências, orientando e abrindo espaço para interação e socialização, por isso com o desenvolvimento de projetos procura-se desenvolver no aluno a capacidade de agir eficazmente nas situações que surgem desde o planejamento até a execução do mesmo.

Assim, pode-se perceber que a utilização de um projeto para demonstrar um conteúdo se mostrou bastante eficaz, uma vez que possibilitou que os alunos discutissem entre si, em casa, com os pais e questionassem a professora de Biologia sobre determinadas características das plantas medicinais e o seu uso correto. 
Vol. 2, n. 3 - Edição Especial: Ciclos Formativos em Ensino de Ciências.

O educando é agente do próprio saber o qual na medida em que é socialmente construído, faz sentido para ele. O ensino deve estimular a curiosidade e articular conhecimentos com competências.

\section{REFERÊNCIAS}

ABDALA, D.F. Circuito florístico: uma estratégia para o ensino de botânica. ENCICLOPÉDIA BIOSFERA, Centro Científico Conhecer- Goiânia, v. 10, n 18; p.3547-3558, 2014.

BITENCOURT, I.M. A Botânica no Ensino Médio: análise de uma proposta didática baseada nas CTS. Universidade Estadual do Sudoeste da Bahia, Jequié, 2013.

BRASIL. Ministério da Educação. Secretaria de Educação. Parâmetros Curriculares Nacionais: Biologia. Brasília: MEC-SEF, 2016.

KRASILCHIK, M. Prática de Ensino de Biologia, 6ª edição. São Paulo: Harbra, 1996.

SILVA, L. CVALLET, V.J.; ALQUINI, Y. O professor, o aluno e o conteúdo no ensino de botânica. Educação, Santa Maria, v. 1, nº 1, p.67-80, 2006.

TOMAZZONI, M. I.; NEGRELle, R. R. B. CENTA, M. L. Fototerapia Popular: A Busca Instrumental Enquanto Prática Terapêutica. Texto Contexto Enferm, V. 15, n. $1,2006$. 